\title{
Mycobacterium leprae downregulates the expression of PHEX in Schwann cells and osteoblasts
}

\author{
Sandra R Boiça Silva', Antônio J Tempone ${ }^{2}$, Tatiana P Silva ${ }^{2}$, Maria Renata SN Costa ${ }^{3}$, \\ Geraldo MB Pereira ${ }^{1,2}$, Flávio A Lara ${ }^{2}$, Maria Cristina V Pessolani², Danuza Esquenazi ${ }^{1,2} /+$ \\ 'Laboratório de Imunopatologia, Faculdade de Ciências Médicas, Universidade do Estado do Rio de Janeiro, Rio de Janeiro, RJ, Brasil \\ ${ }^{2}$ Laboratório de Microbiologia, Instituto Oswaldo Cruz-Fiocruz, Av. Brasil 4365, 21045-900 Rio de Janeiro, RJ, Brasil \\ ${ }^{3}$ Divisão de Pesquisa e Ensino, Instituto Lauro de Souza Lima, Departamento de Saúde de São Paulo, Bauru, SP, Brasil
}

Neuropathy and bone deformities, lifelong sequelae of leprosy that persist after treatment, result in significant impairment to patients and compromise their social rehabilitation. Phosphate-regulating gene with homologies to endopeptidase on the X chromosome (PHEX) is a Zn-metalloendopeptidase, which is abundantly expressed in osteoblasts and many other cell types, such as Schwann cells, and has been implicated in phosphate metabolism and $X$-linked rickets. Here, we demonstrate that Mycobacterium leprae stimulation downregulates PHEX transcription and protein expression in a human schwannoma cell line (ST88-14) and human osteoblast lineage. Modulation of PHEX expression was observed to a lesser extent in cells stimulated with other species of mycobacteria, but was not observed in cultures treated with latex beads or with the facultative intracellular bacterium Salmonella typhimurium. Direct downregulation of PHEX by M. leprae could be involved in the bone resorption observed in leprosy patients. This is the first report to describe PHEX modulation by an infectious agent.

Key words: Mycobacterium leprae - leprosy - PHEX - osteoblasts - Schwann cells

Leprosy remains an important cause of morbidity with approximately 200,000 new cases per year (WHO 2009). Mycobacterium leprae, the causative agent of leprosy, is the unique obligate intracellular pathogen able to invade the peripheral nervous system, in which it is predominantly found inside Schwann cells. This tissue tropism is the basis of the characteristic nerve damage associated with leprosy, often leading to peripheral neuropathy, a severe sequela of leprosy that is common in endemic countries (Scollard et al. 2006). Increasing efforts over the past decade to understand important early events in the interaction of $M$. leprae with peripheral nerves have resulted in the characterization of bacterial adhesins and receptors involved in $M$. leprae attachment to Schwann cells (de Melo Marques et al. 2000, Rambukkana 2004, Soares de Lima et al. 2005). The effects of M. leprae on myelin sheath integrity (Rambukkana et al. 2002, Tapinos et al. 2006) and on Schwann cell proliferation (Tapinos \& Rambukkana 2005) have been investigated as well.

In contrast, the mechanisms underlying leprosy-induced bone damage have not been thoroughly explored. Facial and acral skeletal deformities are historic hallmarks of leprosy and are part of the disease's stigmata (Illarramendi et al. 2001, Britton \& Lockwood 2004). Bone damage occurs in approximately $80 \%$ of leprosy

Financial support: CNPq (481489/2004-5) (to MCVP)

+ Corresponding author: danuza@ioc.fiocruz.br

Received 10 December 2009

Accepted 19 May 2010 patients (Choudhuri et al. 1999); the small bones of the hands and feet, followed by the bones of the face, are most frequently affected. Histologically, these lytic bone lesions present foamy macrophages with numerous bacilli, few lymphocytes, epithelioid cells and Langhans giant cells (Job 1963, Dave et al. 2004). Bone is a dynamic tissue characterized by continuous formation and resorption. Bone formation predominates in growing bone, whereas resorption often predominates in aging bone, leading to osteopenia and osteoporosis. Many disease states may also lead to bone fragility (Hardy \& Cooper 2009).

The Zn-metalloendopeptidase phosphate-regulating gene with homologies to endopeptidase on the $\mathrm{X}$ chromosome (PHEX) is a key regulatory protein in hydroxyapatite formation and bone mineralization (Rowe et al. 2004). The PHEX gene encodes a 749 amino acid protein, which is a member of the M13 family of type II zinc-dependent proteases that is expressed ubiquitously in all vertebrate tissues (Turner \& Tanzawa 1997, KiryuSeo \& Kiyama 2004).

The primary mechanism by which PHEX regulates mineralization involves its binding in osteoblasts to matrix extracellular phosphoglycoprotein (MEPE), protecting it from hydrolysis by cathepsin B proteases (Guo et al. 2002). The secretion of cathepsin $B$ proteases by osteoblasts is markedly stimulated by parathyroid hormone, a bone-resorbing hormone (Aisa et al. 1996), which is known to be elevated in leprosy patients (Ishikawa et al. 2001, Ribeiro et al. 2007). MEPE proteolysis generates the protease-resistant acidic serine aspartate rich MEPE associated motif (ASARM) peptide, which directly inhibits calcium oxalate crystallization and crystal growth on the extracellular matrix (Hoyer et al. 2001) and promotes inhibition of the renal NPT2 phosphate co-trans- 
porter, affecting renal phosphate handling (Rowe et al. 2004). The MEPE-derived ASARM peptide must be phosphorylated to play its role as a PHEX substrate (Addison et al. 2008).

It was recently demonstrated that osteopontin (OPN), a member of the small integrin-binding ligand $\mathrm{N}$-linked glycoproteins family, is also a source of ASARM peptide. Phosphorylated ASARM peptide derived from OPN was able to inhibit mineralization in osteoblast cultures and the addition of PHEX rescues this effect (Addison et al. 2010). Consequently, a possible dual mechanism for PHEX has been suggested: to prevent the release of ASARM peptides from proteins like MEPE and OPN and to promote ASARM's degradation.

Additionally, it has been demonstrated that PHEX participates in the dismutation of FGF23, a hormone produced by osteocytes, the brain and parathyroid glands, which downregulates NPT2 expression in kidney proximal tubules. FGF23 downregulates matrix proteins, such as osteocalcin and sialoprotein, which are both required for osteogenesis and reduces 1-alpha-hydroxylase vitamin D levels, resulting in hypophosphatemia, renal phosphate wastage and osteomalacia (Liu et al. 2007, Tenenhouse 2007).

The bone injuries observed in leprosy may be related to the previously described mechanisms of increased bone resorption, but this bone damage is also associated with the bacterial modulation of molecules involved in bone mineralization and phosphate homeostasis. The purpose of this paper was to verify possible effects of M. leprae infection in osteoblasts and Schwann cells on PHEX transcription and expression.

\section{PATIENTS, MATERIALS AND METHODS}

Cell lines and bacteria - The ST88-14 schwannoma cell line was isolated from a patient with neurofibromatosis type I (kindly donated by Prof J Fletcher, Harvard University, USA) and was maintained in supplemented Roswell Park Memorial Institute medium $[10 \%$ fetal calf serum (FCS), $10 \mathrm{mM}$ Hepes, $100 \mathrm{U} \mathrm{mL}^{-1}$ penicillin, $100 \mu \mathrm{g} \mathrm{mL}^{-1}$ streptomycin, $2 \mathrm{mM}$ L-glutamine; Gibco BRL]. Human osteoblast lineage (HOB), primary HOB (kindly donated by Dr FC Silva, Federal University of Rio de Janeiro, Brazil), were cultured in Dulbecco's Modified Eagle's Medium (Invitrogen) supplemented with $10 \%$ FCS, $1 \%$ minimum essential amino acid medium solution (Sigma), $0.15 \mathrm{~g} \mathrm{~L}^{-1}$ ascorbic acid (Sigma), $10 \mathrm{mM}$ Hepes and $14.3 \mathrm{mM} \mathrm{NaHCO}$. Irradiated armadillo-derived $M$. leprae was prepared as previously described (Shepard et al. 1980) and kindly provided by $\mathrm{Dr}$ Patrick Brennan (through National Institutes of Health contract). Mycobacterium bovis bacillus CalmetteGuérin (BCG) (Pasteur 1173P2 WHO) and Mycobacterium smegmatis (ATCC 19420) were grown at $37^{\circ} \mathrm{C}$ in Middlebrook $7 \mathrm{H} 9$ broth (Difco Laboratories) supplemented with $0.05 \%$ Tween $80,2 \%$ glycerol and ADC supplement (Sigma). Salmonella typhimurium (x3179) was grown in sterile brain heart infusion medium (Becton Dickinson) at $37^{\circ} \mathrm{C}$ with shaking $(160 \mathrm{rpm})$. Bacteria were harvested in mid-log phase, gamma irradiated $\left(10^{5}\right.$ rads $)$ and kept frozen $\left(-80^{\circ} \mathrm{C}\right)$ until use.
Reverse transcription-polymerase chain reaction $(R T-P C R)$ - Cells incubated with or without $M$. leprae for four and $24 \mathrm{~h}$ were washed with phosphate buffered saline (PBS), pH 7.2, after which whole RNA was extracted with Trizol, according to supplier recommendations (Invitrogen). Two micrograms of total RNA were reversely transcribed or not (mock cDNA) with SuperScript II (200 U/reaction; Invitrogen). Semi-quantitative RT-PCR reactions were performed with specific primers for the human PHEX gene (Fow-5'-CAGAGTGGTTTACAAATCCGACG-3', Rev-5'- TTCTCCCAGGGTCCTCTTCC-3') and for the endogenous control glyceraldehyde-3-phosphate dehydrogenase (GAPDH) gene (Fow-5'-GGAAACTGTGGCGTGAT-3', RevI-5'-AAAGGTGGAGGAGTGGGT-3' and RevII5'-GCAACTGTGCGGAGGG-3'). Primers were used in optimized PCR conditions to ensure generation of amplicons during the exponential phase of reactions. The PCR reactions were conducted in $30 \mu \mathrm{L}$ of buffer (50 $\mathrm{mM} \mathrm{KCl}, 10 \mathrm{mM}$ Tris- $\mathrm{HCl}, 1 \%$ Triton X-100, $2.0 \mathrm{mM}$ $\mathrm{MgCl}_{2}, \mathrm{pH}$ 8.4) with $1 \mu \mathrm{M}$ primers, $0.2 \mathrm{mM}$ dNTPs and $0.5 \mathrm{U}$ of Taq polymerase (Amersham-Pharmacia) or DNA polymerase (Promega). Amplicons were determined by electrophoresis in a $2 \%$ agarose gel and stained with ethidium bromide. Images were captured by a Kodac DC290 camera and the densitometric analysis was carried out using 1D 3.6 Kodak software.

Flow cytometry - Confluent cultures of ST88-14 and HOB cells were incubated with lethally-irradiated $M$. leprae, $M$. bovis BCG, M. smegmatis, S. typhimurium at $37^{\circ} \mathrm{C}$ in a humidified atmosphere of $5 \% \mathrm{CO}_{2}$ for 24 or $48 \mathrm{~h}$ at a ratio of 50 bacteria per cell. Control cultures were incubated with polystyrene beads $(3 \mu \mathrm{m}$ diameter; Sigma) at a 50:1 ratio. After incubation, cells were detached by trypsinization and washed with PBS with $10 \%$ FCS. Cells were resuspended in cytometry buffer (PBS, supplemented with $0.1 \%$ sodium azide and $3 \%$ FCS) and incubated with anti-PHEX antibody $\left(4 \mu \mathrm{g} \mathrm{mL}^{-1}\right.$; Alpha Diagnostic Int) or with $\mathrm{IgG}$ isotype during $30 \mathrm{~min}$ at $4^{\circ} \mathrm{C}$ in the dark. After washing, cells were resuspended in cytometry buffer and incubated with anti-IgG FITClabeled antibody (Dako) during $30 \mathrm{~min}$ at $4^{\circ} \mathrm{C}$ in the dark. Cells were then washed and fixed with $1 \%$ paraformaldehyde (Sigma) in PBS. Ten thousand cells were analyzed with a FACSCalibur flow cytometer using Cell Quest software (Becton-Dickinson).

Immunocytofluorescence - HOB cells were cultured on glass coverslips and incubated with $M$. leprae that had been previously stained with $60 \mu \mathrm{M}$ propidium iodide (PI) (Molecular Probes) for $48 \mathrm{~h}$. Cells were extensively washed with PBS, pH 7.2, fixed with $4 \%$ paraformaldehyde (Sigma) for $15 \mathrm{~min}$ at $4{ }^{\circ} \mathrm{C}$ and permeabilized with Perm 2 (Becton-Dickinson) for $5 \mathrm{~min}$. After blocking with $5 \%$ bovine serum albumin for $30 \mathrm{~min}$, cells were incubated overnight with polyclonal anti-PHEX antibody $\left(8 \mu \mathrm{g} \mathrm{mL}^{-1}\right)$ at $4^{\circ} \mathrm{C}$. Cells were then washed and incubated with FITC-conjugated anti-IgG antibody (Dako) for $30 \mathrm{~min}$ at $4^{\circ} \mathrm{C}$ in the dark. Negative controls were established by omitting the primary antibody. Cell nuclei were stained with 4',6-diamidino- 
2-phenylindole (Molecular Probes; $1 \mu \mathrm{g} \mathrm{mL-1} \mathrm{in} \mathrm{PBS).}$ The glass slides were analyzed under ultraviolet illumination on a Nikon Eclipse E400 fluorescence microscope. Confocal images were acquired using a Zeiss Meta 510 laser-scanning microscope (Carl Zeiss).

Statistical analysis - Comparisons between groups were performed by a one-way analysis of variance (ANOVA) and Tukey's multiple comparison test. Differences of $p<0.001$ were considered significant. ANOVA and Tukey's test were performed using GraphPad Prism version 4.00 for Windows (GraphPad Software, San Diego, CA, USA).

\section{RESULTS}

We first evaluated PHEX gene and protein expression in the human schwannoma cell line ST88-14 following infection with $M$. leprae. Semi-quantitative RTPCR showed time-dependent downregulation of PHEX mRNA in M. leprae-infected cells, in a time-dependent way (Fig. 1A). Densitometric analysis of RT-PCR products revealed that $M$. leprae infection, after $24 \mathrm{~h}$, inhibited PHEX mRNA synthesis by approximately $75 \%$ compared to its basal level (Fig. 1B). The effect of $M$. leprae on Schwann cell PHEX expression at the protein level was investigated by flow cytometric analysis using anti-PHEX specific antibodies; we found that $M$. leprae efficiently inhibited PHEX expression after $24 \mathrm{~h}$ of infection (Fig. 1C). Cultures treated with M. leprae for $48 \mathrm{~h}$ had similar PHEX protein levels (data not shown).

Because PHEX also plays a direct and local role in modulating osteoblastic activity and mineralization, protecting the MEPE peptide from hydrolysis, we analyzed whether $M$. leprae infection modulates the expression of PHEX in primary HOB cultures. Fig. 2 shows semi-quantitative RT-PCR analysis of PHEX expression in HOB cells that had been treated for four and $24 \mathrm{~h}$ with M. leprae (Fig. 2A). Densitometric analysis of the RT-PCR gel revealed that $M$. leprae was able to downregulate PHEX expression in osteoblasts to levels similar to those observed in Schwann cells (Fig. 2B).

Subsequently, we evaluated whether protein synthesis is also affected in HOB cells. Fig. 3 shows PHEX expression in HOB cells measured by flow cytometry. The inhibition of PHEX expression is shown as percentage values, using non-infected control cells as a reference, after 24 and $48 \mathrm{~h}$ of treatment with $M$. leprae, M. bovis (BCG), M. smegmatis, S. typhimurium or latex beads. PHEX downregulation was clearly observed following stimulation with M. leprae and was most pronounced at $48 \mathrm{~h}$ of infection (Fig. 3, black bar). Non-pathogenic mycobacteria also stimulated negative PHEX modulation in a time-dependent fashion, but to a lesser extent than M. leprae. Another intracellular pathogen, S. typhimurium, was unable to induce any significant change in PHEX expression, which suggests a mycobacterial-specific effect. As expected, no dramatic change in PHEX expression was observed after incubation with latex beads.

Expression of PHEX by HOB cells was observed by immunocytofluorescence and anti-PHEX reactivity was
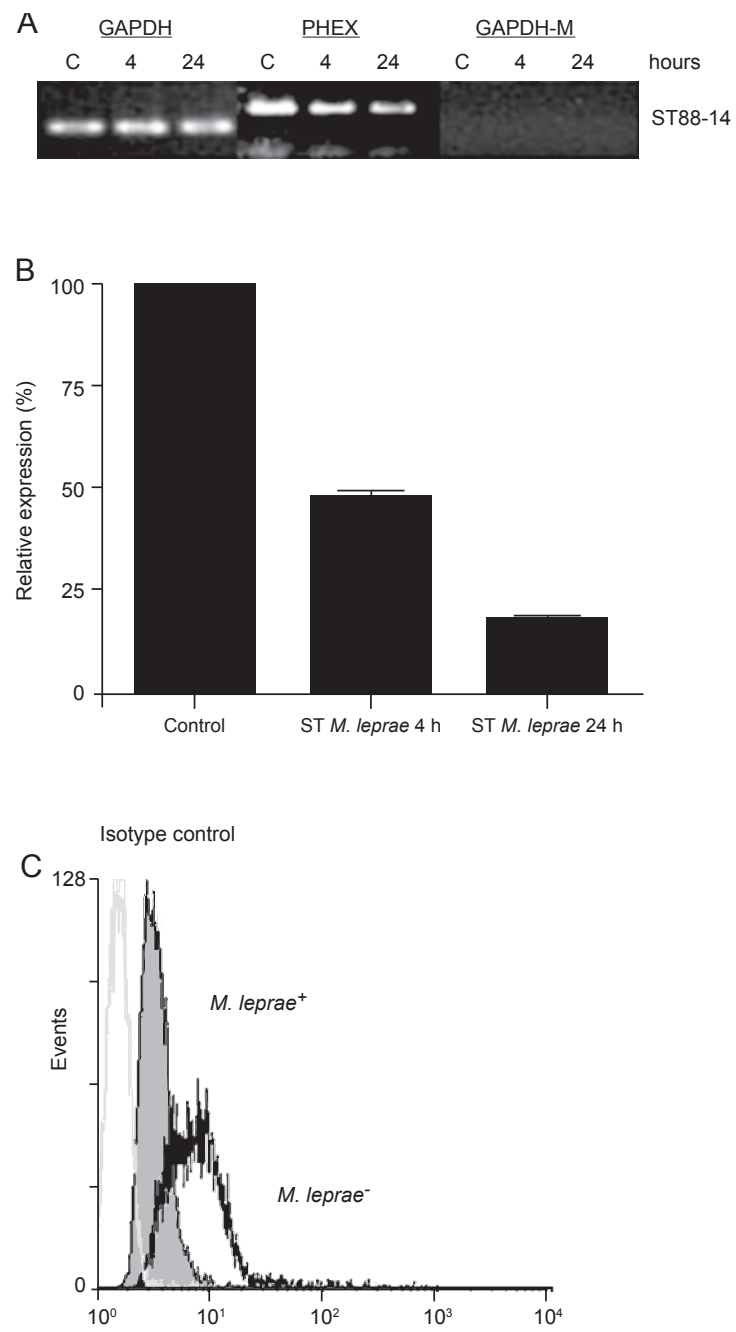

Fig. 1: inhibition of human Schwann cells phosphate-regulating gene with homologies to endopeptidase on the $\mathrm{X}$ chromosome (PHEX) expression by Mycobacterium leprae. A: eletrophoretic profile of reverse transcription-polymerase chain reaction (RT-PCR) using ST8814 cDNA incubated with and without $M$. leprae as template. Semiquantitative RT-PCR showing decrease in the number of mRNA molecules from the PHEX gene in ST 88-14 cells incubated with $M$. leprae during indicated time. Reactions with glyceraldehyde-3-phosphate dehydrogenase mock (GAPDH-M) cDNA revealed the absence of genomic DNA contamination; B: densitometry analysis indicated a reduction of approximately $80 \%$ of PHEX expression in ST88-14 cells treated with $M$. leprae during $24 \mathrm{~h}$; C: flow cytometry assay showed decreased number of PHEX protein exposure on the ST88-14 cell surface after $M$. leprae incubation during $24 \mathrm{~h}$. The numbers indicate the fluorescence intensity median of PHEX expression. Results are representative of five experiments.

predominantly observed in the perinuclear region (Fig. 4A). In cells treated for $24 \mathrm{~h}$ with PI-M. leprae, an evident decrease in protein expression was observed (Fig. 4B). Bacterial internalization by osteoblasts was confirmed by performing confocal image studies, which exhibited M. leprae stained with PI in the same focal plane as the cell nucleus (Fig. 4C) and showed that they were not only associated with the osteoblast membrane. 
A
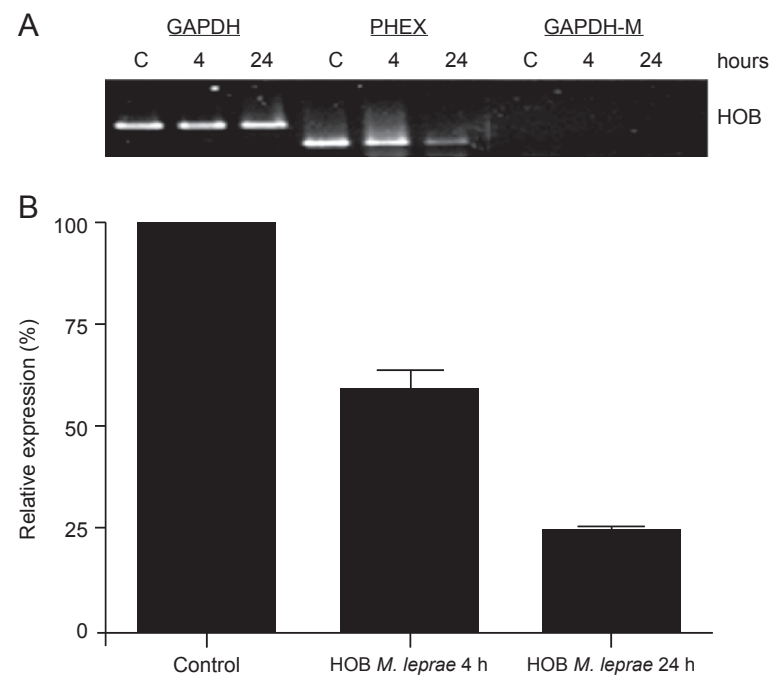

Fig. 2: inhibition of human osteoblasts phosphate-regulating gene with homologies to endopeptidase on the $\mathrm{X}$ chromosome (PHEX) expression by Mycobacterium leprae. A: semi-quantitative reverse transcription-polymerase chain reaction (RT-PCR) showing downregulation of PHEX gene transcription in human osteoblast lineage (HOB) cells exposed to $M$. leprae. Reactions with mock glyceraldehyde-3-phosphate dehydrogenase mock (GAPDH-M) cDNA revealed the absence of genomic DNA contamination; B: densitometry analysis of the agarose gel indicates an approximate reduction of $80 \%$ in the PHEX expression in HOB cells treated $24 \mathrm{~h}$ with $M$. leprae. RT-PCR results are representative of three experiments.

\section{DISCUSSION}

Bone deformities are hallmarks of leprosy, which are characterized by bone loss of the nasal spine, maxillary structures, hands and feet. Many factors may contribute and interact to cause bone injuries in leprosy patients. Bone resorption in chronic inflammatory diseases is related to an increase in osteoclast activity mediated by inflammatory cytokines (Jimi et al. 2004, Koga et al. 2004). Factors such as malnutrition, paralysis and even peripheral neuropathy predisposing to trauma have also been implicated in bone and joint lesions in leprosy (Carayon \& Languillon 1985). Furthermore, during the course of the disease, leprosy patients often present with acute inflammatory episodes, known as reactions which are treated with long-term glucocorticoid (GC) therapy, which likely contributes to bone loss (Sugumaran 1998). Indeed, an excess of circulating GC has adverse effects on bone architecture, leading to a reduction in osteogenesis, osteoblast proliferation and production of specific proteins and interfering with a range of important signaling pathways (Cooper 2004, Canalis et al. 2007, Hurson et al. 2007). Nevertheless, the effects of GC use are almost indistinguishable from those of the underlying inflammatory diseases, the pathological hallmarks of which commonly include bone resorption (Hardy \& Cooper 2009). Notably, multibacillary leprosy patients typically present with bone damage prior to receiving any treatment (Job 1963).

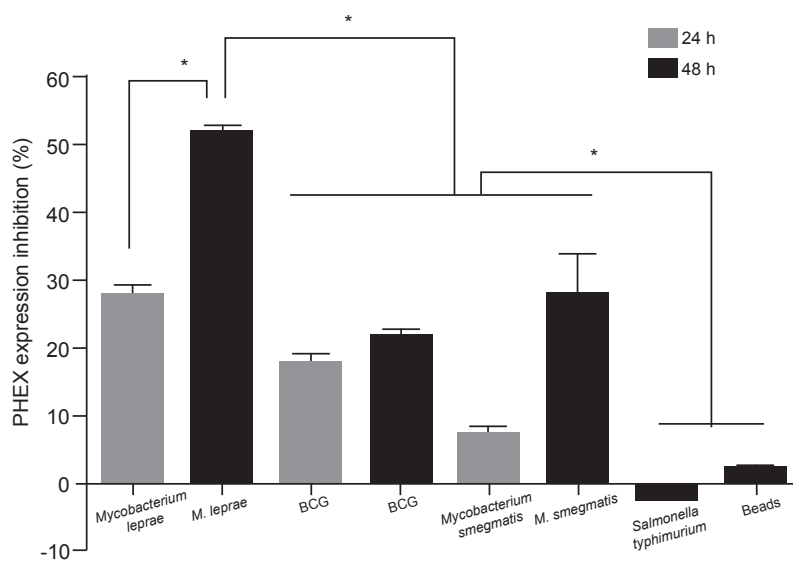

Fig. 3: phosphate-regulating gene with homologies to endopeptidase on the X chromosome (PHEX) expression inhibition observed by osteoblasts' flow cytometry. Osteoblasts were exposed to different pathogens and membrane PHEX was revealed by immunostained after 24 (white bars) and $48 \mathrm{~h}$ (black bars) of incubation. Results are expressed as percentage of PHEX expression inhibition, using cell control fluorescence intensity median as $100 \%$ of PHEX expression parameter. Asterisks mean differences considered significant $(\mathrm{p}<$ 0.001). Results are representative of three experiments. BCG: bacillus Calmette-Guérin.

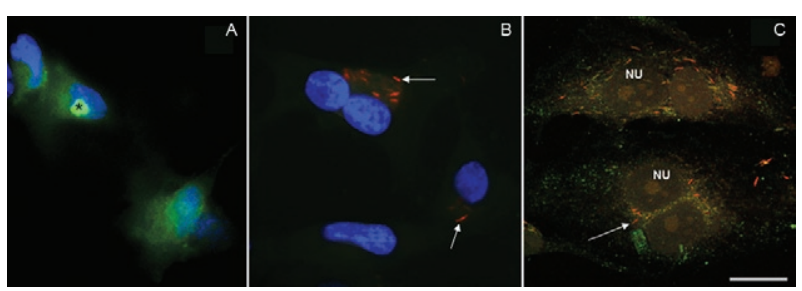

Fig. 4: immunocytochemistry of phosphate-regulating gene with homologies to endopeptidase on the X chromosome (PHEX) in osteoblasts. A: epifluorescence microscopy by immunocytofluorescence of human osteoblast lineage (HOB) culture showing normal PHEX expression evidenced by anti-PHEX FITC antibody. Asterisk points mineralization aggregate; B: culture of $\mathrm{HOB}$ cells after $48 \mathrm{~h}$ incubation with propidium iodide (PI) labeled-Mycobacterium leprae (arrows). A striking decrease of PHEX expression is observed and mineralization aggregates are no more visible. Nuclei were stained by 4,6-diamidino-2-phenylindole; C: confocal sections in the nuclear (NU) plane of osteoblasts in division evidencing intracellular PI labeled-M. leprae (arrows). Images are representative of three experiments. Bars: $20 \mu \mathrm{m}$.

In addition to elucidating the contributing factors to bone disease, the study of the mechanisms of bone mineralization and phosphate control uncovered a critical functional protein, the substrate of which was unknown for many years. PHEX is now implicated in harboring extracellular matrix proteins, such as MEPE and OPN, and preventing the release of ASARM peptides. PHEX also cleaves these peptides, which are direct and potent inhibitors of bone mineralization. An indirect effect of PHEX absence or downregulation must be verified in 
the kidneys by observation of phosphatonins, such as FGF23, or even ASARM fragments.

Although osteoblasts are not considered classical targets of M. leprae, we successfully infected primary HOB in vitro and observed PHEX downregulation in this cell type. Apart from osteoblast infection, PHEX was also decreased in Schwann cells that are non-osteogenic. The importance of this negative modulation is that we can add mineralization defects to the list of well-known factors that interact to produce leprotic bone disease. For example, osteoporotic-inducing $\mathrm{GC}$ is also involved in the control of PHEX expression, which involves an atypical GC response element located in its promoter region (Hines et al. 2002). Thus, the balance between bone formation and resorption results in the clinical presentation of the patient.

The development of downregulatory mechanisms in PHEX expression could be advantageous to M. leprae. In fact, there is a chain of events initiated by PHEX downregulation that generates high levels of serum FGF23, which consequently suppresses the expression of $1 \alpha$-hydroxylase and increases 24 -hydroxylase in the kidney, leading to 1,25-vitamin D3 (calcitriol) deprivation. Calcitriol, recently identified as an immune modulator, is involved in the shift from a Th1 to Th2 response and in the regulation of macrophage differentiation (Vlotides et al. 2007, Daniel et al. 2008). Calcitriol also augments the transcription of cathelicidin, which encodes an antimicrobial peptide important in mycobacterial killing (Martineau et al. 2007, Cooper 2009). In addition to the role of PHEX downregulation in leprotic bone damage, calcitriol-related changes in the immune response may also contribute to the bone damage seen with M. leprae. However, this and other hypotheses must be satisfactorily explored after further detailed studies.

In our study, PHEX modulation was observed in another two tested types of mycobacteria, although it was more evident in M. leprae. PHEX modulation is similar in Schwann cells and osteoblasts, indicating the potential role of $M$. leprae in inhibiting this gene. In multibacillary patients, it is possible that this mechanism may be relevant to the pathophysiology of bone damage.

Schwann cells are the main target of M. leprae infection in vivo, and PHEX is constitutively expressed in abundance in the human sural nerve (unpublished observations) and in the HMS-97 schwannoma cell line (John et al. 2001). We found that these cells also exhibit PHEX downregulation after $M$. leprae infection, corroborating PHEX modulation as a probable important mechanism in the pathogenesis of mycobacteria.

The presence of PHEX detected by our immunocytochemical analysis in the perinuclear region suggests its continuous synthesis associated with the Golgi apparatus and the endoplasmic reticulum, as previously shown in murine osteoblasts (Thompson et al. 2002). Our results provide further evidence that $M$. leprae is directly involved in the downregulation of PHEX expression, probably leading to an imbalance in bone turnover.
We demonstrate herein that M. leprae is capable of inhibiting PHEX expression in osteoblasts in a very similar manner as that observed in Schwann cells, indicating that the bacillus modulates PHEX in both osteogenic and non-osteogenic cells. In multibacillary leprosy patients, $M$. leprae infects a large range of tissues and may induce profound PHEX inhibition in target cells, leading to extensive bone disease. Moreover, it has recently been shown that TNF- $\alpha$ induces reductions in PHEX expression and mineralization in mice (Uno et al. 2006). Because it is well-known that TNF plays a role in the pathophysiology of leprosy, aggravating both neural and bone damage (Sarno \& Sampaio 1996), the possible participation of this cytokine in contributing to the functional alteration in PHEX expression during the course of leprosy is an attractive speculation. As far as we know, our study is the first report to describe PHEX modulation by M. leprae and may be useful in uncovering new therapeutic alternatives for bone injuries in leprosy.

\section{ACKNOWLEDGEMENTS}

To Dr Jason Fletcher, for providing the ST88-14 schwannoma cell line, to Dr Fernando C Silva, for ceding the human osteoblast lineage, to Luciana S Rodrigues and Marjorie M Guimarães, for technical support, to Dr Pedro P Manso (Laboratory of Pathology-Fiocruz), for the use of a confocal microscope platform, and to Katia B Magalhães, for carefully editing the text.

\section{REFERENCES}

Addison WN, Masica DL, Gray JJ, McKee MD 2010. Phosphorylationdependent inhibition of mineralization by osteopontin ASARM peptides is regulated by PHEX cleavage. J Bone Miner Res 25: 695-705.

Addison WN, Nakano Y, Loisel T, Crine P, McKee MD 2008. MEPEASARM peptides control extracellular matrix mineralization by binding to hydroxyapatite: an inhibition regulated by PHEX cleavage of ASARM. J Bone Miner Res 23: 1638-1649.

Aisa MC, Rahman S, Senin U, Maggio D, Russell RG 1996. Cathepsin $\mathrm{B}$ activity in normal human osteoblast-like cells and human osteoblastic osteosarcoma cells (MG-63): regulation by interleukin-1 beta and parathyroid hormone. Biochim Biophys Acta 1290: 29-36.

Britton WJ, Lockwood DN 2004. Leprosy. Lancet 363: 1209-1219.

Canalis E, Mazziotti G, Giustina A, Bilezikian JP 2007. Glucocorticoid-induced osteoporosis: pathophysiology and therapy. Osteoporos Int 18: 1319-1328.

Carayon A, Languillon J 1985. Osteoarticular lesions in leprosy (experience 1960-1982). Acta Leprol 3: 133-153.

Choudhuri H, Thappa DM, Kumar RH, Elangovan S 1999. Bone changes in leprosy patients with disabilities/deformities (a clinicoradiological correlation). Indian J Lepr 71: 203-215.

Cooper AM 2009. Cell-mediated immune responses in tuberculosis. Annu Rev Immunol 27: 393-422.

Cooper MS 2004. Sensitivity of bone to glucocorticoids. Clin Sci (Lond) 107: 111-123.

Daniel C, Sartory NA, Zahn N, Radeke HH, Stein JM 2008. Immune modulatory treatment of trinitrobenzene sulfonic acid colitis with calcitriol is associated with a change of a T helper (Th) $1 /$ Th17 to a Th2 and regulatory T cell profile. J Pharmacol Exp Ther 324: 23-33. 
Dave S, Nori AV, Thappa DM, Siddaraju N 2004. Leprous osteitis presenting as bone cyst and erosions. Dermatol Online J 10: 17.

de Melo Marques MA, Mahapatra S, Nandan D, Dick T, Sarno EN, Brennan PJ, Vidal Pessolani MC 2000. Bacterial and host-derived cationic proteins bind alpha2-laminins and enhance Mycobacterium leprae attachment to human Schwann cells. Microbes Infect 2: $1407-1417$.

Guo R, Rowe PS, Liu S, Simpson LG, Xiao ZS, Quarles LD 2002. Inhibition of MEPE cleavage by Phex. Biochem Biophys Res Commun 297: 38-45.

Hardy R, Cooper MS 2009. Bone loss in inflammatory disorders. J Endocrinol 201: 309-320.

Hines ER, Collins JF, Jones MD, Serey SH, Ghishan FK 2002. Glucocorticoid regulation of the murine PHEX gene. Am J Physiol Renal Physiol 283: 356-363.

Hoyer JR, Asplin JR, Otvos L 2001. Phosphorylated osteopontin peptides suppress crystallization by inhibiting the growth of calcium oxalate crystals. Kidney Int 60: 77-82.

Hurson CJ, Butler JS, Keating DT, Murray DW, Sadlier DM, O’Byrne JM, Doran PP 2007. Gene expression analysis in human osteoblasts exposed to dexamethasone identifies altered developmental pathways as putative drivers of osteoporosis. BMC Musculoskelet Disord 8: 12.

Illarramendi X, Carregal E, Nery JA, Sarno EN 2001. Progression of acral bone resorption in multibacillary leprosy. Acta Leprol 12: 29-37.

Ishikawa A, Ishikawa S, Hirakawa M 2001. Osteoporosis, bone turnover and hypogonadism in elderly men with treated leprosy. Lepr Rev 72: 322-329.

Jimi E, Aoki K, Saito H, D’Acquisto F, May MJ, Nakamura I, Sudo T, Kojima T, Okamoto F, Fukushima H, Okabe K, Ohya K, Ghosh S 2004. Seletive inhibition of NF-kappa B blocks osteoclastogenesis and prevents inflammatory bone destruction in vivo. Nat Med 10: 617-624.

Job CK 1963. Pathology of leprous osteomyelitis. Int J Lepr 31: 26-33.

John MR, Wickert H, Zaar K, Jonsson KB, Grauer A, Ruppersberger P, Schmidt-Gayk H, Murer H, Ziegler R, Blind E 2001. A case of neuroendocrine oncogenic osteomalacia associated with a PHEX and fibroblast growth factor-23 expressing sinusidal malignant schwannoma. Bone 29: 393-402.

Kiryu-Seo S, Kiyama H 2004. DINE (damage induced neuronal endopeptidase). Protein Pept Lett 11: 451-460.

Koga T, Inui M, Inoue K, Kim S, Suematsu A, Kobayashi E, Iwata T, Ohnishi H, Matozaki T, Kodama T, Taniguchi T, Takayanagi H, Takai T 2004. Costimulatory signals mediated by the ITAM motif cooperate with RANKL for bone homeostasis. Nature 428: 758-763.

Liu S, Gupta A, Quarles LD 2007. Emerging role of fibroblast growth factor 23 in a bone-kidney axis regulating systemic phosphate homeostasis and extracellular matrix mineralization. Curr Opin Nephrol Hypertens 16: 329-335.

Martineau AR, Wilkinson KA, Newton SM, Floto RA, Norman AW, Skolimowska K, Davidson RN, Sørensen OE, Kampmann B, Griffiths CJ, Wilkinson RJ 2007. IFN-gamma- and TNF-independent vitamin D-inducible human suppression of mycobacteria: the role of cathelicidin LL-37. J Immunol 178: 7190-7198.
Rambukkana A 2004. Mycobacterium leprae-induced demyelination: a model for early nerve degeneration. Curr Opin Immunol 16: $511-518$

Rambukkana A, Zanazzi G, Tapinos N, Salzer JL 2002. Contact-dependent demyelination by Mycobacterium leprae in the absence of immune cells. Science 296: 927-931.

Ribeiro FB, Pereira F de A, Muller E, Foss NT, de Paula FJ 2007. Evaluation of bone and mineral metabolism in patients recently diagnosed with leprosy. Am J Med Sci 334: 322-326.

Rowe PS, Kumagai Y, Gutierrez G, Garrett IR, Blacher R, Rosen D, Cundy J, Nawab S, Chen D, Drezner MK, Quarles LD, Mundy GR 2004. MEPE has the properties of an osteoblastic phosphatonin and minhibin. Bone 34: 303-319.

Sarno EN, Sampaio EP 1996. Role of inflammatory cytokines in tissue injury in leprosy. Int J Lepr Other Mycobact Dis 64 (Suppl. 4): $269-273$.

Scollard DM, Adams LB, Gillis TP, Krahenbuhl JL, Truman RW, Williams DL 2006. The continuing challenges of leprosy. Clin Microbiol Rev 19: 338-381.

Shepard CC, Draper P, Rees RJ, Lowe C 1980. Effect of purification steps on the immunogenicity of Mycobacterium leprae. Br J Exp Pathol 61: 376-379.

Soares de Lima C, Zulianello L, Marques MA, Kim H, Portugal MI, Antunes SL, Menozzi FD, Ottenhoff TH, Brennan PJ, Pessolani MC 2005. Mapping the laminin-binding and adhesive domain of the cell surface-associated Hlp/LBP protein from Mycobacterium leprae. Microbes Infect 7: 1097-1109.

Sugumaran DS 1998. Leprosy reactions - complications of steroid therapy. Int J Lepr Other Mycobact Dis 66: 10-15.

Tapinos N, Ohnishi M, Rambukkana A 2006. ErbB2 receptor tyrosine kinase signaling mediates early demyelination induced by leprosy bacilli. Nat Med 12: 961-966.

Tapinos N, Rambukkana A 2005. Insights into regulation of human Schwann cell proliferation by Erk $1 / 2$ via a MEK-independent and p56Lck-dependent pathway from leprosy bacilli. Proc Natl Acad Sci USA 102: 9188-9193.

Tenenhouse HS 2007. Phosphate transport: molecular basis, regulation and pathophysiology. J Steroid Biochem Mol Biol 103: 572-577.

Thompson DL, Sabbagh Y, Tenenhouse HS, Roche PC, Drezner MK, Salisbury JL, Grande JP, Poeschla EM, Kumar R 2002. Ontogeny of Phex/PHEX protein expression in mouse embryo and subcellular localization in osteoblasts. J Bone Miner Res 17: 311-320.

Turner AJ, Tanzawa K1997. Mammalian membrane metallopeptidases: NEP, ECE, KELL, and PEX. FASEB J 11: 355-364.

Uno JK, Kolek OI, Hines ER, Xu H, Timmermann BN, Kiela PR, Ghishan FK 2006. The role of tumor necrosis factor alpha in down-regulation of osteoblast Phex gene expression in experimental murine colitis. Gastroenterology 131: 497-509.

Vlotides G, Gaertner R, Angstwurm MW 2007. Modulation of monocytic lipopolysaccharide-induced tissue factor expression and tumor necrosis factor alpha release by estrogen and calcitriol. Hormones (Athens) 6: 52-61.

WHO - World Health Organization 2009. Global leprosy situation. WER 84: 333-340. 